\title{
Cost-effectiveness of a primary care model for anxiety disorders
}

Hans-Helmut König, Anja Born, Dirk Heider, Herbert Matschinger, Sven Heinrich, Steffi G. Riedel-Heller, Daniel Surall, Matthias C. Angermeyer and Christiane Roick

\section{Background}

Individuals with anxiety disorders often do not receive an accurate diagnosis or adequate treatment in primary care.

\section{Aims \\ To analyse the cost-effectiveness of an optimised care model for people with anxiety disorders in primary care.}

\section{Method}

In a cluster randomised controlled trial, 46 primary care practices with 389 individuals positively screened with anxiety were randomised to intervention (23 practices, 201 participants) or usual care (23 practices, 188 participants). Physicians in the intervention group received training on diagnosis and treatment of anxiety disorders combined with the offer of a psychiatric consultation-liaison service for 6 months. Anxiety, depression, quality of life, service utilisation and costs were assessed at baseline, 6-month and 9-month follow-up.

\section{Results}

No significant differences were observed between intervention and control group on the Beck Anxiety Inventory, Beck Depression Inventory and EQ-5D during follow-up. Total costs were higher in the intervention group (€4911 v. $€ 3453, P=0.09$ ). The probability of an incremental cost-effectiveness ratio $<€ 50000$ per quality-adjusted life year was below $10 \%$.

\section{Conclusions}

The optimised care model did not prove to be cost-effective.

\section{Declaration of interest}

None.
Up to $20 \%$ of individuals attending primary care are affected by anxiety disorders. ${ }^{1,2}$ As anxiety disorders are often associated with medically unexplained physical symptoms ${ }^{3}$ many people do not receive accurate diagnosis or adequate treatment in primary care ${ }^{4}$ and this results in high medical costs ${ }^{5}$ due to costly medical testing $^{6}$ or the use of inappropriate and expensive emergency services. ${ }^{7}$ Even when diagnosed accurately, only a few receive guideline-level pharmacotherapy or psychotherapy. ${ }^{4,8,9}$ Although in Germany people have direct access to office-based psychiatrists and psychotherapists and do not need a referral, a large proportion of individuals with anxiety disorders are managed solely in primary care. ${ }^{10}$

So far only two randomised controlled trials (RCTs) showed that early diagnosis and subsequent adequate treatment of anxiety disorders in primary care may increase the cost-effectiveness of care. ${ }^{11,12}$ Unlike these studies where interventions were primarily targeted directly at people affected by anxiety disorders, the present study analysed an optimised care model for anxiety disorders in primary care that consisted of an intervention primarily targeted at primary care physicians (general practitioners, GPs). This intervention, which was composed of specific training combined with the offer of a psychiatric consultation-liaison service for GPs, might be comparatively easy to implement in the healthcare system as training courses are very common in continuing medical education. ${ }^{13}$ The purpose of this study was to analyse the cost-effectiveness of this optimised care model from a societal perspective.

\section{Method}

\section{Sample}

Primary care practices and screened individuals

All 315 GP practices in the city area of Leipzig, Germany, were informed about the study by mail, of which 54 volunteered to participate. All participating GP practices were run by a single GP, the most common practice type in Germany. In these practices, 8605 consecutive patients aged 18 to 65 were screened for anxiety disorders using the German version of the Patient Health Questionnaire (PHQ-D) ${ }^{14,15}$ from August to November 2005. General practitioners and their assistants had no specific psychiatric skills. Terminally ill or suicidal individuals, people with cognitive impairment as well as those with insufficient command of the German language were excluded from screening. Three hundred and sixty-two people returned incomplete questionnaires, resulting in 8243 PHQ-D questionnaires available for analysis. Of these, $629(7.6 \%)$ screened positive for anxiety disorders. General practitioners were not informed about the screening results. In four GP practices no individuals screened positive as a result of a lack of adherence to the study protocol. These practices were excluded from further analysis.

\section{Study participants}

Of the 629 individuals who screened positive, 389 (61.8\%) participated in the baseline data collection after providing informed consent. Reasons for non-participation in the study were: withdrawal of study participation by four GPs $(4.3 \%$ of positively screened individuals), no postal/telephone contact possible (7.6\%), no interest/no time (6.2\%), distrust (1.7\%), severe illness $(0.5 \%)$, no response at baseline despite consent (4.9\%), unknown reason (13.0\%). There were no significant differences between participants and non-participants with respect to type of anxiety disorder, age, gender, living situation and employment.

\section{Cluster randomisation}

After grouping GP practices into four strata according to the quartiles of the number of positively screened people, GP practices 
(clusters) were randomly allocated within each stratum to an intervention group or a control group, following the design of a cluster randomised controlled trial. Stratified randomisation was carried out by an individual outside the research team using a computer generated program and resulted in 23 GP practices in the intervention group and 23 in the control group. The number of participants at baseline was $n=201$ in the intervention group and $n=188$ in the control group. The research team and GP practices remained masked to randomisation until after baseline data had been collected. After baseline, the research assistant could not be kept masked to allocation of GPs as she organised the intervention and liaised with practice receptionists. However, to avoid systematic bias only self-reported outcome measures for participants were used. Participants were not informed whether their GP was allocated to the intervention group or the control group. There were no significant differences between participants in the intervention group and the control group with respect to sociodemographic characteristics and type of anxiety disorder at baseline (online Table DS1). Figure 1 shows a CONSORT diagram outlining the flow of clusters and participants through the trial. ${ }^{16}$

\section{Intervention}

The intervention consisted of specific training for GPs combined with the offer of a psychiatric consultation-liaison service in treating anxiety disorders. The intervention aimed at improving GPs' diagnostic and therapeutic knowledge and skills through a cognitive-behavioural therapy (CBT) approach as used in psychiatry. The theoretical background of training and consultation was based on current guidelines for the treatment of anxiety disorders ${ }^{17,18}$ and drew on a graduated scheme for diagnosis and treatment designed by the German Society of Psychiatry, Psychotherapy and Nervous Diseases (DGPPN). ${ }^{19}$

The $10 \mathrm{~h}$ training, split across two afternoons within 2 weeks, included three sessions covering: clinical diagnostics and differential diagnosis of anxiety disorders; guidelines for efficient pharmacotherapy; and the cognitive-behavioural concept of anxiety development. Two further sessions were used for role play training of non-medical techniques such as key counselling skills, information for the patient about a psychiatric diagnosis as well as psychological and psychiatric treatment options, and guidance for the patient about exposition or relaxation treatment. Limits of medical treatment in GP practice were also discussed. Thus, both knowledge transfer of the guidelines for management of anxiety disorders and basic training in using CBT techniques were included in the training. Multiple methods of instruction, including discussion, tutorial, video and exercise, were applied to ensure task relevance, high learner involvement in setting educational goals and skill practice. ${ }^{20}$ Discussion and exercise were case based and derived from GPs' clinical practice. Physician behaviour was discussed after role playing.

Additionally, a flexible psychiatric consultation-liaison service was offered to GPs that included assessment of specific patients with anxiety disorders, advice to GPs and GP training in CBT if required. ${ }^{21}$ This service was offered to GPs for a period of 6

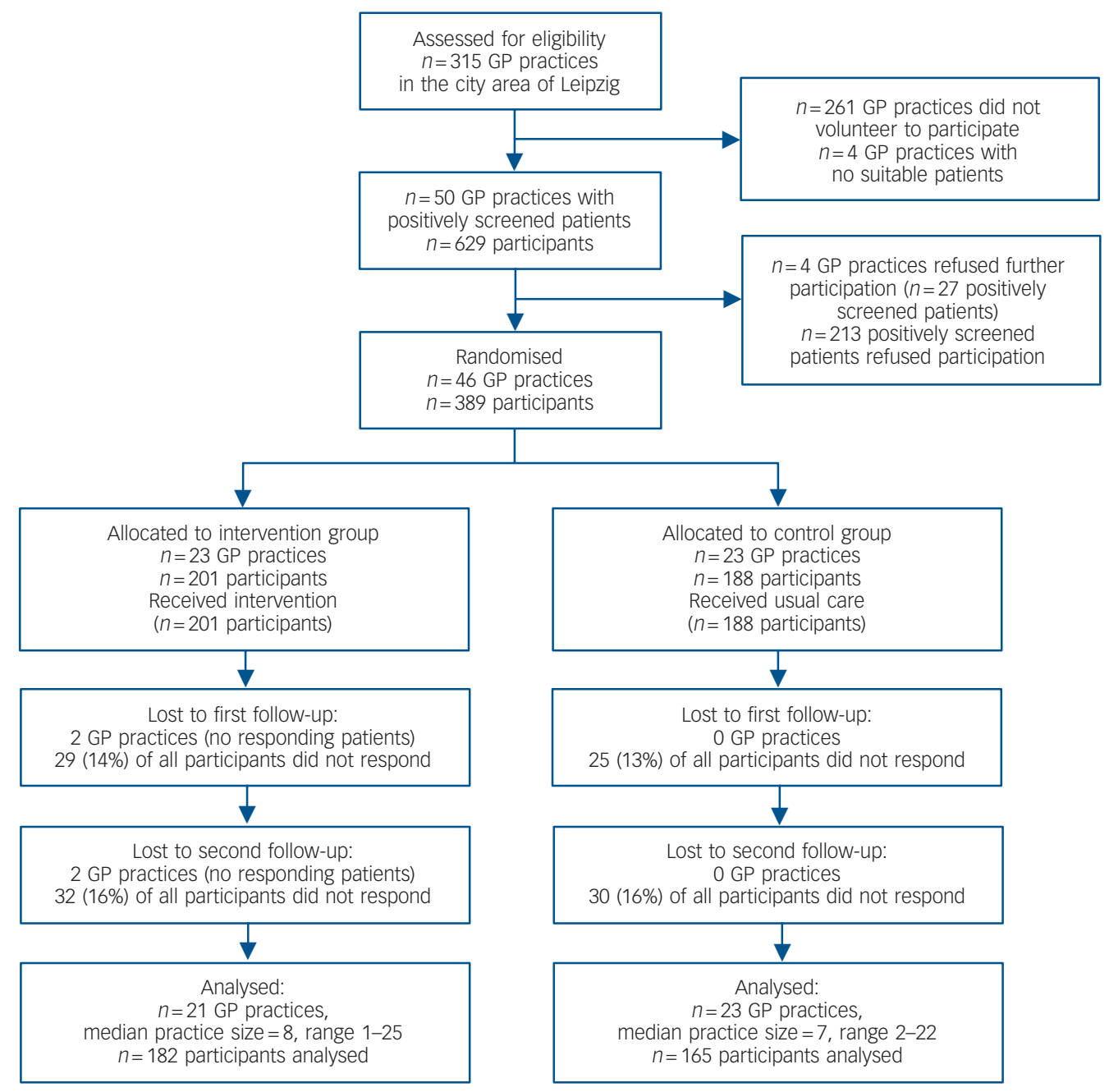

Fig. 1 CONSORT diagram showing the flow of clusters and participants through the trial. 
months starting after the training had been completed (intervention period). ${ }^{21}$ It sought to foster the acquired diagnostic and therapeutic knowledge and to enhance the collaboration among health service providers. The consultation-liaison service was highly flexible, offered at GPs' practices to lower the access barrier for psychiatric services or at the cooperating psychiatric hospital out-patient department at short notice, and were thus superior to standard care.

All GPs in the intervention group received the same training and had the same chance to use the consultation-liaison service. Training and consultations were conducted by a clinical psychologist and a psychiatrist specialised in treatment of anxiety disorders. General practitioners in the control group provided usual care. The training part of the intervention was offered to the participating GPs of the control group at the end of the study's follow-up period for ethical reasons.

\section{Data collection and measures}

All 389 participants received a set of questionnaires by mail at baseline ( $T_{0}$, January to March 2006), at the end of the 6-month intervention period ( $T_{1}$, November 2006) as well as 3 months after the end of the intervention phase $\left(T_{2}\right.$, February 2007). For completing the questionnaires, respondents received an allowance of $€ 20$ at $T_{0}$, and $€ 10$ each at $T_{1}$ and $T_{2}$. Non-responders were contacted by telephone once after 4 weeks and were asked to return the completed questionnaires. Drop-out rates were relatively low, resulting in $335(86.1 \%)$ participating patients at $T_{1}$ (intervention group: $n=172$; control group: $n=163$ ) and 327 (84.1\%) patients at $T_{2}$ (intervention group: $n=169$; control group: $n=158$ ). Whereas the PHQ-D was used for screening, data collection at $T_{0}, T_{1}$, and $T_{2}$ included the Beck Anxiety Inventory (BAI), Beck Depression Inventory (BDI-II), the EQ-5D as well as a questionnaire of service utilisation and costs.

\section{PHQ-D}

Modules three, four and five of the German long version of the $\mathrm{PHQ}^{14}$ were used to screen primary care patients for symptoms of anxiety disorders according to ICD-10 criteria $^{22}$ for panic disorder (F41.0), panic disorder with agoraphobia (F40.01), generalised anxiety disorder (F41.1) or unspecified anxiety disorder (F41.9). The PHQ is a clinically efficient self-administered screening tool for common mental health disorders. It contains 22 items specifically measuring anxiety symptoms that are rated for presence and extent of symptoms. An anxiety disorder is diagnosed above a score of five symptoms present according to the algorithms provided by the manual. ${ }^{14}$ Patient Health Questionnaire anxiety diagnoses showed good concordance with those of independent health professionals (kappa 0.65, sensitivity $63 \%$, specificity $97 \%$, overall accuracy $91 \%)^{15}$ and a high positive predictive value. $^{23}$

\section{BAI}

The BAI is a 21-item measure designed to assess the severity of self-reported anxiety. ${ }^{24}$ Responses on each item range from 0 (not at all bothered) to 3 (severely bothered), resulting in a possible total score range from 0 to 63 . Higher scores indicate higher levels of anxiousness.

\section{BDI-II}

The BDI-II is a 21-item self-report depression screening measure. ${ }^{25}$ The items ask respondents to endorse statements characterising how they have been feeling throughout the past week. Thereby each item is rated on a scale ranging from 0 to 3 , with a possible range of total scores from 0 to 63 . Higher scores represent a higher intensity of depression.

\section{EQ-5D}

The EQ-5D is a generic health-related quality of life questionnaire that comprises five questions (items) relating to current problems in the dimensions: mobility; self-care; usual activities; pain/ discomfort; and anxiety/depression. ${ }^{26}$ Responses in each dimension are divided into three ordinal levels coded: 1 , no problems; 2, moderate problems; 3, extreme problems. Theoretically, $3^{5}=243$ different health states can be defined by the EQ-5D descriptive system. The EQ-5D also includes a visual analogue scale (EQ-VAS), similar to a thermometer, ranging from 0 (worst imaginable health state) to 100 (best imaginable health state) which records the respondent's self-rated valuation of health state (EQ-VAS score). Furthermore, according to a particular set of societal preference values derived from surveys of the general population, an index score (EQ-5D index) for each of the 243 EQ-5D health states is available for various countries, with the best state (perfect health) and 'death' being assigned values of one and zero, respectively. In the present study EQ-5D index scores from the $\mathrm{UK}^{27}$ were used that were derived from a large general population sample $(n=2997)$ and have been used in numerous international studies, including the field of mental health. ${ }^{28}$ Accordingly, to each participant's health status on the descriptive system of the EQ-5D, an EQ-5D index score was assigned.

\section{Questionnaire of service utilisation and costs}

Medical and non-medical resource utilisation was assessed by a questionnaire of service utilisation and costs that was based on questionnaires used in earlier studies ${ }^{29-31}$ and adapted to the purposes of the present study. For a retrospective period of 3 months, the questionnaire covered in-patient care, medical rehabilitation, out-patient physician and non-physician services, medical supply and dentures, pharmaceuticals, transportation, home care, as well as productivity loss due to work loss days (indirect costs). Depending on the service, type, quantity of use or duration were recorded (see Appendix). The instrument is available from the authors. As recommended by German guidelines on health economic evaluation, ${ }^{32}$ costs were measured from a societal perspective in order to measure the impact of the intervention on the welfare of the society as a whole.

\section{Unit costs}

For monetary valuation of resource utilisation, unit costs were determined for all services used and for all medical goods prescribed or privately purchased at 2006 price levels. If cost data were available only for earlier years, costs were inflated to the year 2006 using the consumer price index. ${ }^{33}$ Detailed information regarding monetary valuation is shown in the Appendix. Most unit costs were obtained from a recent guideline for cost calculation in health economic evaluation in Germany. ${ }^{34}$ Costs for medical supply and dentures were calculated using market prices. Pharmaceutical costs were calculated using prices from the German catalogue of drugs. ${ }^{35}$ Costs for travel on public transport or in taxis were calculated according to patients' specifications. Costs of car travel were calculated according to the number of kilometres travelled multiplied by a flat rate of $€ 0.30$ per kilometre (according to the tax-deductible rate allowed for trips to and from work in Germany). Informal care provided by relatives and friends was valued by the mean net income per h (€18.30) in Germany, corresponding to an opportunity cost approach as recommended by the guideline ${ }^{34}$ mentioned above. Intervention costs were calculated using market prices. Productivity loss (indirect costs) was quantified based on the human capital approach, valuing illness-related work loss days 
by the mean labour costs per work day $(€ 169)$ in Germany as recommended by the above mentioned guideline. ${ }^{34}$

\section{Intervention costs}

Intervention costs consisted of costs for the specific GP training and costs for consultation-liaison. For GP training, 20 work hours of a psychologist and 10 work hours of a psychiatrist were used, which were monetarily valued at $€ 28$ per $\mathrm{h}$ according to labour costs in tariff class IIa of the German Federal Employee Tariff (Bundesangestelltentarif - BAT) which applied to salaried psychiatrists and physicians working in the public health sector in the year 2006. Costs for the room rent (€200) and printed materials $(€ 20)$ were also considered. In total, 31 consultations were conducted by the psychologist, lasting on average $1.5 \mathrm{~h}$ each, which were also valued at $€ 28$ per $h$. Thus, total intervention costs added up to $€ 2362$, or $€ 11.75$ per participant in the intervention group.

\section{Data analysis}

Incremental cost-effectiveness ratio

The economic analysis aimed at estimating the incremental costeffectiveness ratio (ICER), i.e. the ratio of the differences in mean costs $\bar{C}$ and mean health effects $\bar{E}$ between the intervention group and the control group during the follow-up period lasting from $T_{0}$ to $T_{2}$ :

$$
I C E R=\frac{\bar{C}_{I G}-\bar{C}_{C G}}{\bar{E}_{I G}-\bar{E}_{C G}}=\frac{\Delta \bar{C}}{\Delta \bar{E}}
$$

For estimating mean costs during the follow-up period, individual costs $C$ were calculated for each participant using linear extrapolation between measurement points, taking into account the individual observation time by using the following equation:

$$
C=\frac{C_{T_{1}}}{90} \times \operatorname{days}\left(T_{0} ; T_{1}\right)+\frac{C_{T_{2}}}{90} \times \operatorname{days}\left(T_{1} ; T_{2}\right)
$$

where $C_{T 1}$ and $C_{T 2}$ are the 3 -month costs measured at $T_{1}$ and $T_{2}$, respectively, and days $\left(T_{0} ; T_{1}\right)$ and days $\left(T_{1} ; T_{2}\right)$ are the number of days between the measurement points for the individual patient. Patients were excluded if no information about costs was available at $T_{1}$ and $T_{2}$. If one of the two values (at $T_{1}$ or $T_{2}$ ) was missing it was replaced by the actually existing value. If the individual observation time was missing, the average number of days was employed to compute costs.

Following the concept of cost-utility analysis, quality-adjusted life-years (QALYs) were used as the measure of health effects. ${ }^{36}$ Quality-adjusted life-years were calculated by weighting the duration of health states by the EQ-5D index. For calculation of mean QALYs during the follow-up period, individual QALYs were calculated for each participant using linear interpolation between measurement points and taking into account the individual observation time, using the following equation:

$$
\begin{aligned}
\text { QALYs }= & {\left[\frac{\text { index }_{T_{0}}+\text { index }_{T_{1}}}{2} \times \operatorname{days}\left(T_{0} ; T_{1}\right)\right.} \\
& \left.+\frac{\text { index }_{T_{1}}+\operatorname{index}_{T_{2}}}{2} \times \operatorname{days}\left(T_{1} ; T_{2}\right)\right] / 365
\end{aligned}
$$

where index ${ }_{T 0}$, index $x_{T 1}$ and index $x_{T 2}$ are the EQ-5D index scores measured at $T_{0}, T_{1}$ and $T_{2}$. The procedure to treat missing information described above for costs was also used for the computation of QALYs.

\section{Statistical analysis}

The study was powered to detect a moderate effect size of $d=0.4$ (90\% power, $5 \%$ significance level; two-tailed $t$-test) in the primary clinical outcome measure BAI score. Effect size was assumed to be somewhat smaller than reported for CBT in individuals with anxiety disorders $(d=0.5) .^{37}$ Sample-size calculation took into account the design effect (cluster inflation factor), ${ }^{38}$ assuming an average cluster size of 10 and an intracluster correlation coefficient (ICC) of 0.05 , a magnitude frequently reported for outcome variables. ${ }^{39}$ Sample-size calculation resulted in 19 clusters with 190 people each in the intervention group and control group, which was approximately achieved in the study. Based on this sample size, an ICC of 0.10 would have reduced the study's power to $80 \%$, with all other parameters kept constant.

All statistical analysis was carried out on an intention-to-treat basis using the software package STATA for Windows, Release 10 (STATA Corp., College Station, Texas, USA) and the suite 'bsceaprog.do' for STATA. ${ }^{40}$ For the analysis of differences in means (costs, scores of outcome measures) and for uncertainty analysis of the ICERs, the non-parametric bootstrap procedure (4000 replications) was applied taking into account the cluster design and stratification used in the study. In order to visualise statistical uncertainty of the ICER, cost-effectiveness acceptability curves $^{41}$ were constructed. The level of significance was set at $5 \%$.

\section{Sensitivity analysis}

To analyse the impact of various assumptions made when calculating QALYs and costs, univariate sensitivity analysis was performed by varying the following parameters: instead of the British EQ-5D index scores, EQ-5D index scores derived from a much smaller sample of the German general population $(n=334)^{42}$ and, alternatively, EQ-VAS scores (divided by 100 for transformation to a $0-1$ scale) were used as QALY weights. Instead of the human capital approach, the friction costs approach was used to calculate indirect costs, using a friction period of 49 work days. ${ }^{34}$ Intervention costs were varied by plus and minus $100 \%$. Finally, the ICER was calculated including only complete cases with no missing values.

\section{Ethics}

The research protocol of the study was reviewed and approved by the Committee of Research Ethics at the Medical Faculty of the University of Leipzig.

\section{Results}

\section{Outcome measures}

Table 1 shows the mean scores of outcome measures in the intervention group and the control group at $T_{0}, T_{1}$ and $T_{2}$. At baseline $\left(T_{0}\right)$, the scores of all outcome measures were similar in both groups, with no significant differences. The mean BAI score was 21.25 in the intervention group and 19.51 in the control group.

During follow-up $\left(T_{1}\right.$ and $T_{2}$ ) the scores of most outcome measures tended to improve slightly, with no significant differences between intervention group and control group in scores measured at $T_{1}$ or at $T_{2}$. At $T_{2}$ the mean BAI score was 18.18 in the intervention group and 16.72 in the control group. The ICCs ranged between 0 and 0.11 . In complete cases $v$. cases lost due to drop-out at $T_{1}$ or $T_{2}$, there were no significant differences in any of the outcome measures. 


\begin{tabular}{|c|c|c|c|c|c|c|}
\hline \multirow[b]{2}{*}{ Outcome measure } & \multicolumn{2}{|c|}{ Intervention group } & \multicolumn{2}{|c|}{ Control group } & \multirow[b]{2}{*}{$P^{a}$} & \multirow{2}{*}{$\begin{array}{c}\text { Intracluster } \\
\text { correlation coefficient }\end{array}$} \\
\hline & $n$ & Mean (s.d.) & $n$ & Mean (s.d.) & & \\
\hline \multicolumn{7}{|c|}{ Beck Anxiety Inventory } \\
\hline$T_{0}$ & 169 & $21.25(11.85)$ & 157 & $19.51(11.62)$ & 0.26 & 0.09 \\
\hline$T_{1}$ & 144 & $19.71(11.58)$ & 140 & $16.91(10.33)$ & 0.05 & 0.07 \\
\hline$T_{2}$ & 150 & $18.18(12.17)$ & 145 & $16.72(10.34)$ & 0.34 & 0.07 \\
\hline \multicolumn{7}{|c|}{ Beck Depression Inventory } \\
\hline$T_{0}$ & 177 & $16.29(9.73)$ & 167 & $16.61(10.54)$ & 0.73 & 0.00 \\
\hline$T_{1}$ & 156 & $15.95(10.59)$ & 150 & $14.03(10.33)$ & 0.15 & 0.05 \\
\hline$T_{2}$ & 153 & $15.17(11.15)$ & 142 & $13.93(9.74)$ & 0.35 & 0.03 \\
\hline \multicolumn{7}{|c|}{ EQ-VAS (visual analogue scale) } \\
\hline$T_{0}$ & 198 & $64.83(20.07)$ & 184 & $62.60(21.64)$ & 0.30 & 0.04 \\
\hline$T_{1}$ & 169 & 65.03 (19.79) & 161 & 65.85 (19.69) & 0.74 & 0.06 \\
\hline$T_{2}$ & 163 & $65.83(20.39)$ & 157 & 63.99 (19.98) & 0.42 & 0.02 \\
\hline \multicolumn{7}{|l|}{ EQ-5D index } \\
\hline$T_{0}$ & 193 & $0.66(0.27)$ & 179 & $0.66(0.27)$ & 0.93 & 0.04 \\
\hline$T_{1}$ & 165 & $0.67(0.28)$ & 159 & $0.69(0.24)$ & 0.47 & 0.11 \\
\hline$T_{2}$ & 168 & $0.69(0.28)$ & 154 & $0.68(0.23)$ & 0.84 & 0.11 \\
\hline
\end{tabular}

\section{Costs}

Online Table DS2 presents mean direct and indirect costs in the intervention group and the control group during the 3-month periods preceding $T_{0}, T_{1}$ and $T_{2}$.

During the 3 -month period preceding baseline $\left(T_{0}\right)$, mean direct costs were $€ 1285$ in the intervention group and $€ 1228$ in the control group, with no significant difference between groups. Approximately a third of respondents in both groups (intervention group: $33.8 \%$; control group: $31.9 \%$ ) had used any mental health services, including psychiatric hospital care, out-patient psychiatrists and psychologists, resulting in mean costs per respondent of $€ 466$ (intervention group) and $€ 409$ (control group). The sum of direct and indirect costs (total costs) was $€ 2042$ in the intervention group and $€ 2082$ in the control group with no significant difference between groups.

During follow-up, costs in most categories tended to be lower in the control group, especially costs of in-patient care, resulting in significantly lower direct costs in the control group at $T_{1}$ $(P=0.02)$. The proportion of respondents using mental health services was similar in the intervention group and control group during follow-up, with $31.4 \%$ (intervention group) and $33.1 \%$ (control group) using any service at $T_{1}$, and $33.1 \%$ (intervention group) and $32.9 \%$ (control group) at $T_{2}$. Yet, mean costs of mental health services per respondent tended to be lower in the control group at $T_{1}$ (intervention group: $€ 379$; control group: $€ 139$ ) and $T_{2}$ (intervention group: €353; control group: €158). These non-significant differences were mainly caused by a few more costly users of psychiatric in-patient hospital care in the intervention group than in the control group at $T_{1}$ (intervention group: 3; control group: 1) and $T_{2}$ (intervention group: 4, control group: 2).

During the complete follow-up period mean direct costs calculated according to Equation 2 were $€ 3394$ in the intervention group and $€ 2151$ in the control group. Mean indirect costs due to illness-related work loss days were $€ 1517$ in the intervention group and $€ 1302$ in the control group. Thus, mean total costs were $€ 4911$ in the intervention group and $€ 3453$ in the control group. Differences in direct, indirect and total costs between groups were not significant (Table 2).

\section{QALYS}

The mean duration of follow-up between $T_{0}$ and $T_{2}$ was 290.4 days (s.d. $=25.1$ days) in the intervention group and 285.8 days (s.d. $=19.3$ days) in the control group, corresponding to 0.80 years (s.d. $=0.07$ years) and 0.78 years (s.d. $=0.05$ years), respectively. Mean QALYs calculated according to Equation 3 were 0.5507 in the intervention group and 0.5549 in the control group, with no significant differences between intervention group and control group.

\begin{tabular}{|c|c|c|c|c|c|}
\hline & $\begin{array}{l}\text { Intervention group, } n=182^{\mathrm{a}} \\
\text { Mean (s.d.) }\end{array}$ & $\begin{array}{l}\text { Control group, } n=165^{\mathrm{b}} \\
\text { Mean (s.d.) }\end{array}$ & $\begin{array}{l}\text { Difference } \\
\text { Mean (s.e.) }\end{array}$ & $P^{\mathrm{c}}$ & $\begin{array}{l}\text { Point } \\
\text { estimate }\end{array}$ \\
\hline \multicolumn{6}{|l|}{ Costs, $€$} \\
\hline Direct costs & 3394 (7635) & 2151 (3867) & $1243(674)$ & 0.07 & \\
\hline Total costs & 4911 (9638) & $3453(5612)$ & 1459 (849) & 0.09 & \\
\hline QALYS & $0.5507(0.2344)$ & $0.5549(0.2073)$ & $-0.0042(0.0296)$ & 0.89 & \\
\hline \multicolumn{5}{|l|}{$\begin{array}{l}\text { Based on direct costs } \\
\text { Based on total costs (direct and indirect) }\end{array}$} & $\begin{array}{l}\text { Dominated }^{d} \\
\text { Dominated }^{d}\end{array}$ \\
\hline \multicolumn{6}{|c|}{$\begin{array}{l}\text { a. Differences from } n=201 \text { owing to missing values for cost data during follow-up. } \\
\text { b. Differences from } n=188 \text { owing to missing values for cost data during follow-up } \\
\text { c. Standard error (s.e.) and } P \text { for test of difference in means between intervention and control group are based on non-parametric bootstrapping with } 4000 \text { replications taking into } \\
\text { account clusters and strata. } \\
\text { d. Intervention group was dominated by control group, i.e. the intervention was associated with higher mean costs and fewer mean QALYS. }\end{array}$} \\
\hline
\end{tabular}




\section{Incremental cost-effectiveness ratios}

Mean incremental direct costs during follow-up were $€ 1243$ (95\% CI -79 to 2564), and mean incremental total costs were $€ 1459$ (95\% CI -205 to 3122). Mean incremental QALYs were -0.0042 (95\% CI -0.0622 to 0.0538 ). Thus, point estimates for the ICER showed dominance of the control group, which was associated with lower mean direct costs as well as total costs, and more mean QALYs.

Non-parametric bootstrapping of the distributions of incremental costs and incremental effects resulted in joint densities (Fig. 2) from which cost-effectiveness acceptability curves (Fig. 3) could be derived. For example the probability of an ICER $<50000 € /$ QALY was 3\% when only direct costs were considered and $2 \%$ when total costs were considered.

\section{Sensitivity analysis}

Using German EQ-5D index scores or transformed EQ-VAS scores to value health states resulted in incremental QALYs of -0.0012 (95\% CI -0.0507 to 0.0484$)$ and 0.0058 (95\% CI -0.0382 to 0.0497 ), respectively. Based on German EQ-5D index scores, the point estimates of the ICER showed dominance of the control group; based on EQ-VAS scores the ICER was 215299 $€ /$ QALY for direct costs and $252691 € /$ QALY for total costs, with the probability of an ICER $<50000 € /$ QALY always being below $10 \%$. Using the friction costs approach to calculate indirect costs slightly decreased mean incremental total costs to 1352 (95\% CI -19 to 2723), still resulting in dominance of the control group. Assuming zero or doubled intervention costs hardly changed results, resulting in mean incremental direct and total costs of

(a)

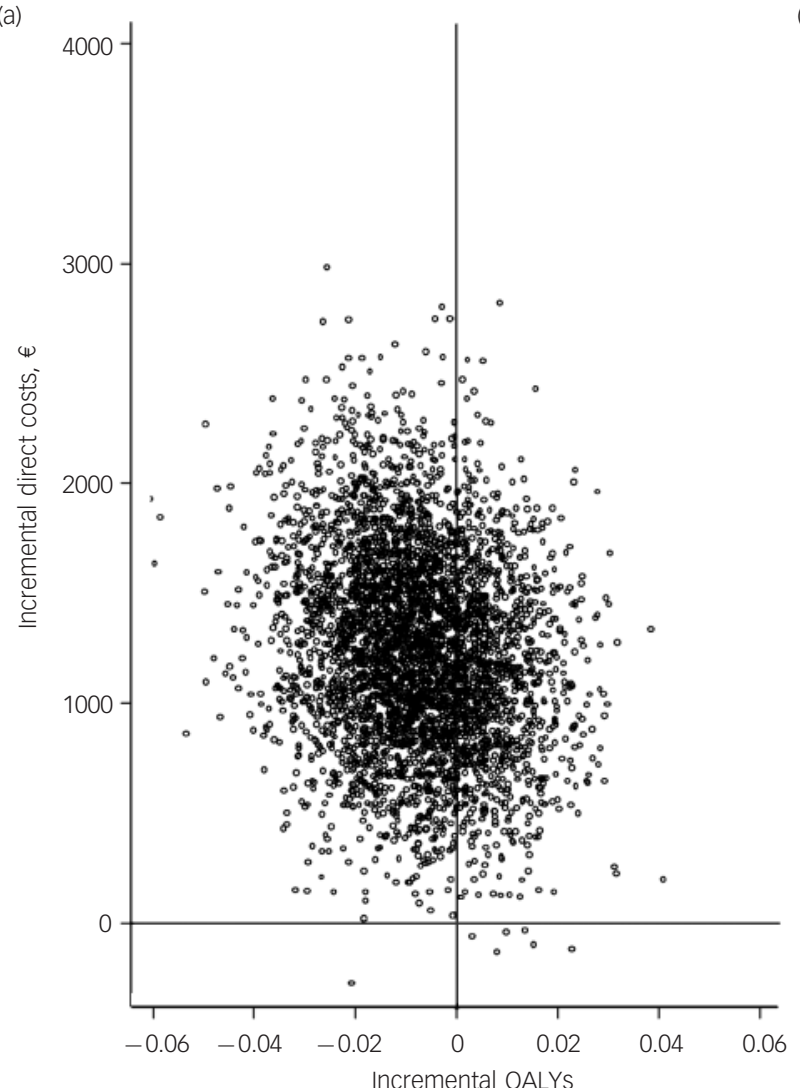

$€ 1231$ (95\% CI -60 to 2522$)$ and $€ 1447$ (95\% CI -246 to 3140 ) or $€ 1255$ (95\% CI -47 to 2556$)$ and $€ 1470$ (95\% CI -242 to 3183), respectively; the respective point estimates for the ICER all showed dominance of the control group. Including only complete cases in the analysis (intervention group $n=159$; control group $n=152$ ) resulted in slightly lower mean incremental direct costs ( $€ 1169,95 \%$ CI -310 to 2648$)$ and total costs ( $€ 1313,95 \%$ CI -572 to 3198 ), similar mean incremental QALYs (0.0069, 95\% CI -0.0071 to 0.0576$)$ and dominance of the control group.

\section{Discussion}

The analysed care model for patients with anxiety disorders consisting of a specific training for GPs combined with the offer of a psychiatric consultation-liaison service did not prove to be cost-effective. During the 9 month follow-up period, neither anxiety symptoms nor health-related quality of life improved significantly more in participants whose GPs received the intervention than in the control group. Direct healthcare costs tended to be higher in participants in the intervention group, resulting in a very low probability of the care model being cost-effective. For example, taking a frequently cited threshold of around $50000 € /$ QALY for healthcare interventions to be considered cost-effective, ${ }^{43}$ the probability of the care model being cost-effective was only $2 \%$ if total costs and societal preference values were used for calculating the ICER. Variation of several assumptions made when calculating costs and QALYs in the sensitivity analysis had hardly any impact on the ICER.

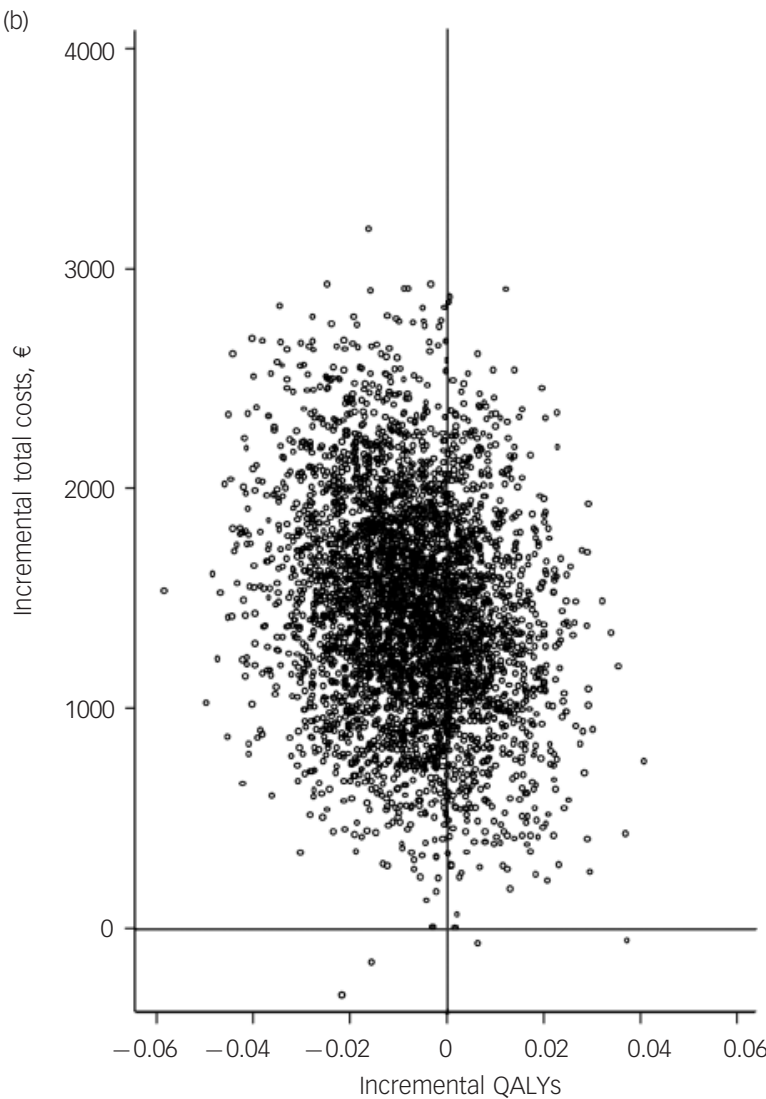

Fig. 2 Joint distribution of incremental (a) direct costs and (b) total costs and incremental quality-adjusted life-years (QALYS) of the optimised care model plotted in the cost-effectiveness plane. Results of non-parametric bootstrapping with 4000 replications taking into account clusters and strata. 


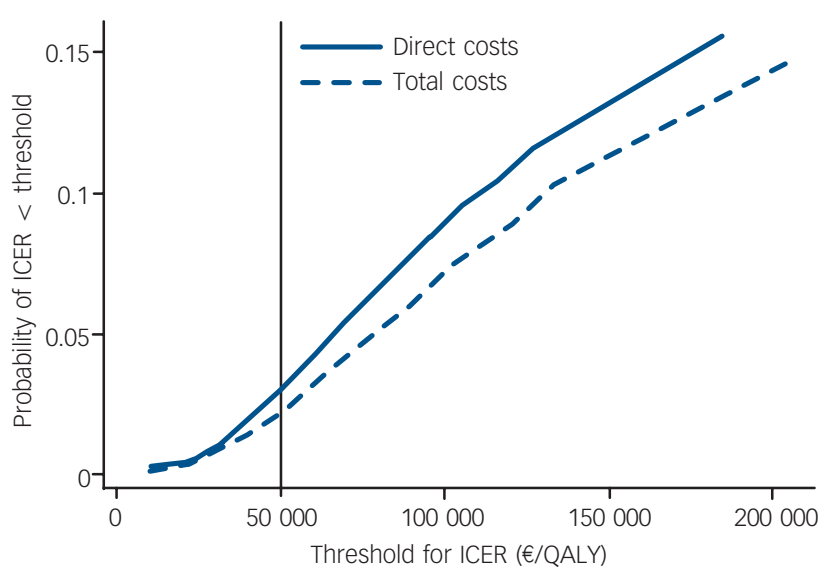

Fig. 3 Cost-effectiveness acceptability curves of the optimised care model taking into account direct costs only or total costs. ICER, incremental cost-effectiveness ratio.

\section{Possible explanations for lack of success}

There are various possible reasons for this care model not being effective. First of all, it is possible that the knowledge and skills acquired by GPs during the training sessions were not sufficient to have a significant impact on diagnostic and therapeutic behaviour and, consequently, on patient outcomes. This is in line with the results of other cluster RCTs that showed that the effectiveness of educational interventions targeted at GPs in the field of mental health tends to be weak. ${ }^{4-46}$ Consisting of 10 hours, the training was probably more profound than in other optimised primary care models for anxiety patients, ${ }^{11,12}$ and evaluation of the training by participating GPs conducted at the end of the last session was excellent (for instance, the mean rating score for the training was 1.04 on a scale ranging from 1 , excellent to 6 , insufficient, and more than $90 \%$ of participating GPs indicated that they had acquired new knowledge). However, GPs seem to need more support to acquire complex mental healthcare skills, such as in $\mathrm{CBT},{ }^{44}$ and more intense practice of these skills, regular reinforcement and auditing may be necessary. In addition to training of GPs, interventions such as the delivery of behavioural and educational self-help materials may be useful to improve the outcomes of individuals with anxiety disorders in primary care, as has been shown for people with depression. ${ }^{47}$

Second, it seems as if the intervention could not sufficiently motivate GPs to use the specific consultation-liaison service or to refer individuals to mental healthcare providers. During the 6-month intervention period only 31 specific consultations were requested by GPs, and the proportion of patients using mental health services did not increase. As GPs in Germany are remunerated according to a fee-for-service system and individuals are free in choosing their physicians, possible reasons may be fears of GPs loosing patients to other providers, which would be associated with a loss of income. It is possible that GPs working in other healthcare systems with different financial incentives may be more motivated to refer individuals to specialists, which limits the generalisabilty of the results reported here.

The cost-effectiveness of this care model targeting patients with anxiety in primary care only indirectly through GPs seems to be much weaker than that of care models that make sure that patients receive at least a basic package of specialised mental health services. In a cost-effectiveness analysis of an RCT, Katon et $a l^{12}$ showed that a collaborative care intervention for people with panic disorder consisting of enhanced patient education and two to three psychiatry visits integrated into primary care was associated with a high probability of lower total ambulatory (out-patient) costs and a higher degree of clinical effectiveness compared with usual care. In another cost-effectiveness analysis, also based on an RCT, Katon et al $^{11}$ showed that a combined CBT and pharmacotherapy intervention for patients with panic disorder in primary care delivered by a mental health therapist was associated with a moderate increase in ambulatory costs and robust clinical improvement compared with usual care.

\section{Limitations}

This study aimed to analyse the cost-effectiveness of the optimised care model under 'real world' conditions. Thus, the design of the study was supposed to represent both the intervention as well as usual care close to what could be achieved under routine care conditions, trying to interfere with real world conditions as little as possible. In other words, this study's design was supposed to analyse effectiveness rather than efficacy. ${ }^{48}$ Consequently, the study had several limitations.

Patients were included in the study based on the results of a screening instrument (PHQ-D) and not on formal diagnosis of an anxiety disorder. As the PHQ has a high specificity (97\%), ${ }^{15}$ probably most of the study participants met formal criteria for anxiety disorders. The mean score of the BAI at baseline was similar to mean BAI scores found in other samples of out-patients with anxiety disorders. ${ }^{24,49}$ On the other hand, the comparatively low sensitivity of the PHQ $(67 \%)^{15}$ resulted in approximately a third of individuals with anxiety disorders being missed, which corresponds to the prevalence of $7.6 \%$ found in our primary care sample as opposed to higher prevalence rates of anxiety found in other primary care samples. ${ }^{1}$ Furthermore, following the 'real world' approach, people who had already used mental healthcare services were not excluded from the study. This might have 'diluted' the effects of the intervention since these individuals may have already received optimal care. However, excluding these people from the analysis did not change the effectiveness nor cost-effectiveness of the care model.

Primary care practices were recruited for the study on a voluntary basis as participation in the optimised care model in the 'real world' would most likely be voluntary too. Thus participating GP practices may not be representative of all GP practices. Of all the patients who screened positive, $62 \%$ participated in the study. This participation rate was comparable with other community-based studies, and comparison of participants and non-participants with respect to sociodemographic variables and type of anxiety disorder did not suggest participation bias. However, participation bias with respect to variables not measured at screening cannot be ruled out, but should be similar in both the intervention group and the control group because of randomisation. Of all participating patients, $86 \%$ responded at $T_{1}$ and $84 \%$ at $T_{2}$. Instead of restricting calculation of the ICER to complete cases, all participants for whom cost data and EQ-5D scores were available at $T_{1}$ or $T_{2}$ were considered, resulting in the ICER being calculated based on $89 \%$ of participants. Thus, only approximately $3 \%$ of variable values missing at $T_{1}$ and $5 \%$ at $T_{2}$ were replaced by the corresponding values measured at $T_{2}$ or $T_{1}$ respectively, which is unlikely to have biased the results. No multiple imputation procedure was adopted since missing values cannot be considered ignorable or missing at random $(\mathrm{MAR})^{50,51}$ and the overall loss was only about $10 \%$. Including only complete cases changed results only marginally, as shown in the sensitivity analysis.

As anxiety disorders have been reported to be associated with increased non-psychiatric medical treatment costs as well as 
reduced productivity, ${ }^{52}$ this study tried to assess all medical and non-medical direct costs as well as indirect costs. Because in Germany no routine database covering all these cost categories exists, costs were calculated based on self-reported data of service use and work loss days, as has been done in many other cost-effectiveness analyses. In order to keep recall bias low, ${ }^{53}$ the period covered by the questionnaire of service utilisation was restricted to 3 months, which meant that costs of the intervention period had to be extrapolated. Whereas recall bias probably leads to underestimation of costs, extrapolation of costs may either overestimate or underestimate costs: overestimation will occur if a high-cost contact occurs during the questionnaire period, because it will be multiplied over the follow-up period; underestimation will occur if a high-cost contact occurs outside the questionnaire period. However, as both the intervention group and the control group were possibly affected by this bias, its effect on the ICER was probably small as the ICER was calculated from differences between intervention group and control group.

Intervention costs per study participant may be overestimated because benefits of the training programme were intended to last longer than the study period and patients not participating in the study may also benefit, which would decrease the costs of the training programme per patient. However, assuming the extreme value of zero intervention costs hardly changed the results, as shown in the sensitivity analysis.

For the cost-effectiveness analysis, QALYs were used as the main measure of health effects, following the concept of costutility analysis, as predominantly recommended by health economists. ${ }^{36,54}$ In the sensitivity analysis, QALYs were calculated using health state valuations derived from the EQ-5D, using social preference values (EQ-5D index), as recommended by health economists, ${ }^{36,54}$ as well as participant preferences (EQ-VAS). The EQ-5D is the most frequently used instrument to calculate QALYs in economic evaluation of healthcare, ${ }^{55}$ and has repeatedly been used in the field of mental health. ${ }^{28,56}$ However, being a generic health status measure, the responsiveness of the EQ-5D to changes in health status of individuals with anxiety disorders may be limited, precluding the detection of small changes. Yet, scores of the disease-specific BAI, which was also used in this study, were not different between the intervention group and the control group either.

\section{Clinical implications}

In conclusion, the care model did not prove to be cost-effective. Knowledge acquired by GPs during the training and/or motivation to refer patients to mental healthcare professionals may have been insufficient to improve diagnosis and treatment of anxiety disorders or reduce costs. Participants in both the intervention group and control group remained persistently symptomatic on the BAI, which highlights the poor prognosis for this disease group. Care models which include at least a basic package of specialised mental health services for people with anxiety disorders in primary care seem more likely to be cost-effective.

\section{Hans-Helmut König, MD, MPH, Health Economics Research Unit, Department of Psychiatry, Anja Born, MSc, Health Economics Research Unit, Department of Psychiatry, and Department of Medical Psychology and Medical Sociology, Dirk Heider, MSc, Health Economics Research Unit, Department of Psychiatry, Herbert Matschinger, PhD, Department of Psychiatry, Sven Heinrich, MSc, Health Economics Research Unit, Department of Psychiatry, Steffi G. Riedel-Heller, MD, MPH, Public Health Research Unit, Department of Psychiatry, Daniel Surall, MSC, Department of Psychiatry, University of Leipzig, Germany; Matthias C. Angermeyer, MD, Center for Public Mental Health, Gösing am Wagram, Austria; Christiane Roick $\mathrm{MD}, \mathrm{MPH}$, Health Economics Research Unit, Department of Psychiatry, University of Leipzig, Germany}

Correspondence: Hans-Helmut König, MPH, University of Leipzig, Health Economics Research Unit, Department of Psychiatry, Liebigstr. 26, D-04103 Leipzig, Germany. Email: hans-helmut.koenig@medizin.uni-leipzig.de

First received 31 Jul 2008, final revision 22 Apr 2009, accepted 6 May 2009

\section{Appendix}

\section{Resources, units and monetary valuation used for calculation of costs}

\begin{tabular}{|c|c|c|c|c|}
\hline Sector & Providers/services/goods & Units & Monetary valuation (unit costs) & Source of unit costs \\
\hline In-patient care & $\begin{array}{l}\text { General hospitals, specialised hospitals } \\
\text { for psychiatric and neurological care }\end{array}$ & Days & $\begin{array}{l}\text { Mean costs per day in } \\
\text { Germany, by hospital type }\end{array}$ & Krauth et al $(2005)^{a, 34}$ \\
\hline Rehabilitation & Rehabilitation hospitals & Days & $\begin{array}{l}\text { Mean costs per day in } \\
\text { Germany }\end{array}$ & Krauth et al $(2005)^{a, 34}$ \\
\hline $\begin{array}{l}\text { Out-patient physician } \\
\text { services }\end{array}$ & $\begin{array}{l}\text { General practitioners, physician specialists, } \\
\text { psychologists and out-patient clinics }\end{array}$ & Contacts & $\begin{array}{l}\text { Mean costs per contact in } \\
\text { Germany, by specialty }\end{array}$ & Krauth et al (2005) $)^{a, 34}$ \\
\hline $\begin{array}{l}\text { Out-patient non-physician } \\
\text { services }\end{array}$ & $\begin{array}{l}\text { For example: physiotherapy, massage, } \\
\text { Iymph drainage, ergotherapy }\end{array}$ & Contacts & $\begin{array}{l}\text { Mean costs per contact in } \\
\text { Germany, by type of service }\end{array}$ & $\begin{array}{l}\text { Krauth et al }(2005)^{a, 34} \\
\text { list of fees paid by AOK }\end{array}$ \\
\hline $\begin{array}{l}\text { Medical supplies } \\
\text { and dentures }\end{array}$ & $\begin{array}{l}\text { Products (e.g. compression stockings, } \\
\text { walking frames) }\end{array}$ & Quantity & Market prices & $\begin{array}{l}\text { Survey of healthcare } \\
\text { equipment suppliers }\end{array}$ \\
\hline Pharmaceuticals & Products & Quantity & Market prices & $\begin{array}{l}\text { Rote Liste Service } \mathrm{GmbH} \\
2006^{35}\end{array}$ \\
\hline Transportation & $\begin{array}{l}\text { Transportation by car, public transport, } \\
\text { taxi or ambulance to medical visits or } \\
\text { treatment }\end{array}$ & km, quantity & $\begin{array}{l}€ 0.30 / \mathrm{km} \text { for car driving, } \\
\text { market prices for other types } \\
\text { of transport }\end{array}$ & $\begin{array}{l}\text { German tax law, costs } \\
\text { reported by respondents }\end{array}$ \\
\hline Home care & $\begin{array}{l}\text { Care provided at home by home help, } \\
\text { relatives or friends }\end{array}$ & Hours & $\begin{array}{l}\text { Mean labour costs for home } \\
\text { help/mean net income per } \mathrm{h} \\
\text { for relatives and friends }\end{array}$ & Krauth et al (2005) $)^{a, 34}$ \\
\hline Intervention costs & $\begin{array}{l}\text { Psychologist, psychiatrist, room rent, } \\
\text { print materials }\end{array}$ & $\begin{array}{l}\text { See methods } \\
\text { section }\end{array}$ & Market prices & Own calculations \\
\hline Indirect costs & Work loss days due to illness & Days & $\begin{array}{l}\text { Mean labour costs per day } \\
\text { in Germany }\end{array}$ & Krauth et al (2005) $)^{a, 34}$ \\
\hline
\end{tabular}




\section{Funding}

This study was funded by the German Federal Ministry of Education and Research (grant number 01GL0502)

\section{References}

1 Kroenke K, Spitzer RL, Williams JB, Monahan PO, Lowe B. Anxiety disorders in primary care: prevalence, impairment, comorbidity, and detection. Ann Intern Med 2007; 146: 317-25.

2 Wittchen HU. Generalized anxiety disorder: prevalence, burden, and cost to society. Depress Anxiety 2002; 16: 162-71.

3 Simon GE, VonKorff M. Somatization and psychiatric disorder in the NIMH Epidemiologic Catchment Area study. Am J Psychiatry 1991; 148: 1494-500.

4 Stein MB, Sherbourne CD, Craske MG, Means-Christensen A, Bystritsky A, Katon W, et al. Quality of care for primary care patients with anxiety disorders. Am J Psychiatry 2004; 161: 2230-7.

5 Konnopka A, Leichsenring F, Leibing E, König HH. Cost-of-illness studies and cost-effectiveness analyses in anxiety disorders: a systematic review. J Affect Disord 2009; 114: 4-31.

6 Katon W. Panic disorder: relationship to high medical utilization, unexplained physical symptoms, and medical costs. J Clin Psychiatry 1996; 57 (suppl 10): s11-8.

7 Kolbasovsky A, Reich L, Futterman R, Meyerkopf N. Reducing the number of emergency department visits and costs associated with anxiety: a randomized controlled study. Am J Manag Care 2007; 13: 95-102.

8 Beesdo K, Krause P, Höfler M, Wittchen HU. Do primary care physicians know generalized anxiety disorders? Estimations of prevalence, attitudes and interventions (in German). Fortschr Med Orig 2001; 119 (suppl 1): s13-6.

9 Roy-Byrne PP, Stein MB, Russo J, Mercier E, Thomas R, McQuaid J, et al. Panic disorder in the primary care setting: comorbidity, disability, service utilization, and treatment. J Clin Psychiatry 1999; 60: 492-9.

10 Wittchen HU, Hoyer J, Höfler M, Krause P. Family physician's interventions and prescribing practice. Results of the GAD-P study (in German). Fortschr Med Orig 2001; 119 (suppl 1): s36-41.

11 Katon W, Russo J, Sherbourne C, Stein MB, Craske M, Fan MY, et al. Incremental cost-effectiveness of a collaborative care intervention for panic disorder. Psychol Med 2006; 36: 353-63.

12 Katon WJ, Roy-Byrne PP, Russo J, Cowley D. Cost-effectiveness and cost offset of a collaborative care intervention for primary care patients with panic disorder. Arch Gen Psychiatry 2002; 59: 1098-104.

13 Marinopoulos SS, Dorman T, Ratanawongsa N, Wilson LM, Ashar BH, Magaziner JL, et al. Effectiveness of continuing medical education. Evid Rep Technol Assess 2007; 149: 1-69.

14 Löwe B, Spitzer RL, Zipfel S, Herzog W. Gesundheitsfragebogen für Patienten (PHQ-D). Komplettversion und Kurzform. Testmappe mit Manual, Fragebögen, Schablonen [Patient Health Questionnaire (PHQ-D): Complete Version and Short Version. Manual, Questionnaires and Templates]. Pfizer, 2002.

15 Spitzer RL, Kroenke K, Williams JB. Validation and utility of a self-report version of PRIME-MD: the PHQ primary care study. Primary Care Evaluation of Mental Disorders. Patient Health Questionnaire. JAMA 1999; 282: 1737-44.

16 Campbell MK, Elbourne DR, Altman DG. CONSORT statement: extension to cluster randomised trials. BMJ 2004; 328: 702-8.

17 American Psychiatric Association. Practice Guideline for the Treatment of Patients with Acute Stress Disorder and Posttraumatic Stress Disorder. APA 2004 (http://www.psychiatryonline.com/pracGuide/ loadGuidelinePdf.aspx?file=ASD_PTSD_05-15-06).

18 Canadian Psychiatric Association. Clinical practice guidelines. Management of anxiety disorders. Can J Psychiatry 2006; 51 (suppl 2): s7-92.

19 Dengler W, Selbmann HK. Leitlinien zu Diagnostik und Therapie von Angsterkrankungen; Praxisleitlinien in Psychiatrie und Psychotherapie (Bd. 2) [Guidelines for Diagnosis and treatment of Anxiety Disorders. Practice Guidelines for Psychiatry and Psychotherapy (vol. 2)]. Steinkopf, 2000.

20 Laidley TL, Braddock III CH. Role of adult learning theory in evaluating and designing strategies for teaching residents in ambulatory settings. Adv Health Sci Educ Theory Pract 2000; 5: 43-54.

21 Wittmund B, Wilms HU, Bull N, Angermeyer MC. Collaboration of a specialised outpatient clinic with office-based general practitioners and psychiatrists in the treatment of anxiety disorders (in German). Verhaltenstherapie 2003; 13: 284-90.

22 World Health Organization (WHO). The ICD-10 Classification of Mental and Behavioral Disorders: Clinical Descriptions and Diagnostic Guidelines. WHO, 1992.
23 Löwe B, Gräfe K, Zipfel S, Spitzer RL, Herrmann-Lingen C, Witte S, et al. Detecting panic disorder in medical and psychosomatic outpatients: comparative validation of the Hospital Anxiety and Depression Scale, the Patient Health Questionnaire, a screening question, and physicians' diagnosis. J Psychosom Res 2003; 55: 515-9.

24 Beck AT, Epstein N, Brown G, Steer RA. An inventory for measuring clinical anxiety: psychometric properties. J Consult Clin Psychol 1988; 56: 893-7.

25 Beck AT, Steer RA, Ball R, Ranieri W. Comparison of Beck Depression Inventories -IA and -II in psychiatric outpatients. J Pers Assess 1996; 67: 588-97

26 EuroQol Group. EuroQol - a new facility for the measurement of healthrelated quality of life. Health Policy 1990; 16: 199-208.

27 Dolan P. Modeling valuations for EuroQol health states. Med Care 1997; 35 1095-108.

28 Sapin C, Fantino B, Nowicki ML, Kind P. Usefulness of EQ-5D in assessing health status in primary care patients with major depressive disorder. Health Qual Life Outcomes 2004; 2: 20.

29 Luppa M, Heinrich S, Matschinger H, Sandholzer H, Angermeyer MC, König $\mathrm{HH}$, et al. Direct costs associated with depression in old age in Germany. J Affect Disord 2008; 105: 195-204.

30 Heinrich S, Luppa M, Matschinger H, Angermeyer MC, Riedel-Heller SG König $\mathrm{HH}$. Service utilization and health-care costs in the advanced elderly. Value Health 2008; 11: 611-20.

31 Roick C, Kilian R, Matschinger H, Bernert S, Mory C, Angermeyer MC German adaptation of the client sociodemographic and service receipt inventory - an instrument for the cost of mental health care (in German). Psychiatr Prax 2001; 28 (suppl 2): s84-90.

32 Graf von der Schulenburg JM, Greiner W, Jost F, Klusen N, Kubin M, Leidl R, et al. German Recommendations on Health Economic Evaluation: Third and Updated Version of the Hanover Consensus. Value Health 2008; 11: 539-44.

33 Statistisches Bundesamt Deutschland (DESTATIS). Verbraucherpreisindizes für Deutschland 2008 [Consumer Price Indices for Germany 2008] DESTATIS, 2008 (https://www-ec.destatis.de/csp/shop/sfg/ bpm.html.cms.cBroker.cls?cmspath=struktur, vollanzeige.csp\&ID=1023399).

34 Krauth C, Hessel F, Hansmeier T, Wasem J, Seitz R, Schweikert B. Empirical standard costs for health economic evaluation in Germany - a proposal by the working group methods in health economic evaluation (in German). Gesundheitswesen 2005; 67: 736-46.

35 Rote Liste Service GmbH. Rote Liste 2006. Arzneimittelverzeichnis für Deutschland [Red List 2006. Directory of Pharmaceuticals for Germany]. Rote Liste Service $\mathrm{GmbH}, 2006$.

36 Drummond MF, Sculpher MJ, Torrance GW, O'Brien B, Stoddart GL. Methods for the Economic Evaluation of Health Care Programmes. Oxford University Press, 2005.

37 Erickson DH, Janeck AS, Tallman K. A cognitive-behavioral group for patients with various anxiety disorders. Psychiatr Serv 2007; 58: 1205-11.

38 Campbell MK, Mollison J, Grimshaw JM. Cluster trials in implementation research: estimation of intracluster correlation coefficients and sample size. Stat Med 2001; 20: 391-9.

39 Campbell M, Grimshaw J, Steen N. Sample size calculations for cluster randomised trials. Changing Professional Practice in Europe Group. $J$ Health Serv Res Policy 2000; 5: 12-6.

40 Glick H, Doshi J, Sonnad SS, Polsky D. Economic Evaluation in Clinical Trials. Oxford University Press, 2007.

41 Briggs $\mathrm{AH}, \mathrm{O}^{\prime}$ Brien $\mathrm{BJ}$, Blackhouse $\mathrm{G}$. Thinking outside the box: recent advances in the analysis and presentation of uncertainty in costeffectiveness studies. Annu Rev Public Health 2002; 23: 377-401.

42 Greiner W, Claes C, Busschbach JJ, Graf von der Schulenburg JM. Validating the EQ-5D with time trade off for the German population. Eur J Health Econ 2005; 6: 124-30.

43 Hirth RA, Chernew ME, Miller E, Fendrick AM, Weissert WG. Willingness to pay for a quality-adjusted life year: in search of a standard. Med Decis Making 2000; 20: 332-42.

44 King M, Davidson O, Taylor F, Haines A, Sharp D, Turner R. Effectiveness of teaching general practitioners skills in brief cognitive behaviour therapy to treat patients with depression: randomised controlled trial. BMJ 2002; 324 947-50.

45 Downs M, Turner S, Bryans M, Wilcock J, Keady J, Levin E, et al. Effectiveness of educational interventions in improving detection and management of dementia in primary care: cluster randomised controlled study. BMJ 2006; 332: $692-6$.

46 Morriss R, Dowrick C, Salmon P, Peters S, Dunn G, Rogers A, et al. Cluster randomised controlled trial of training practices in reattribution for medically unexplained symptoms. Br J Psychiatry 2007; 191: 536-42. 
47 Robinson $\mathrm{P}$, Katon W, Von Korff M, Bush T, Simon G, Lin E, et al. The education of depressed primary care patients: what do patients think of interactive booklets and a video? J Fam Pract 1997; 44: 562-71.

48 Gray JAM. Evidence-Based Healthcare. How to Make Health Policy and Managment Decisions. Churchill Livingstone, 1997.

49 Fydrich $T$, Dowdall $D$, Chambless DL. Reliability and validity of the Beck Anxiety Inventory. J Anxiety Disord 1992; 6: 55-61.

50 Harel $\mathrm{O}$, Zhou XH. Multiple imputation: review of theory, implementation and software. Stat Med 2007; 26: 3057-77.

51 Tang L, Song J, Belin TR, Unutzer J. A comparison of imputation methods in longitudinal randomized clinical trial. Stat Med 2005; 24: 2111-28.

52 Andlin-Sobocki $\mathrm{P}$, Wittchen HU. Cost of anxiety disorders in Europe. Eur J Neurol 2005; 12 (suppl 1): s39-44.
53 Johnston K, Buxton MJ, Jones DR, Fitzpatrick R. Assessing the costs of healthcare technologies in clinical trials. Health Technol Assess 1999: 3: $1-76$.

54 Gold M, Siegel J, Russel L, Weinstein M. Cost-Effectiveness in Health and Medicine. Oxford University Press, 1996.

55 Rasanen $\mathrm{P}$, Roine E, Sintonen H, Semberg-Konttinen V, Ryynanen OP, Roine R. Use of quality-adjusted life years for the estimation of effectiveness of health care: a systematic literature review. Int J Technol Assess Health Care 2006; 22: 235-41.

56 König HH, Roick C, Angermeyer MC. Validity of the EQ-5D in assessing and valuing health status in patients with schizophrenic, schizotypal or delusional disorders. Eur Psychiatry 2007; 22: 177-87.

\section{Her Kind}

Poem

\section{Anne Sexton}

I have gone out, a possessed witch, haunting the black air, braver at night; dreaming evil, I have done my hitch

over the plain houses, light by light: lonely thing, twelve-fingered, out of mind A woman like that is not a woman, quite. I have been her kind.

I have found the warm caves in the woods, filled them with skillets, carvings, shelves, closets, silks, innumerable goods; fixed the suppers for the worms and the elves: whining, rearranging the disaligned. A woman like that is misunderstood.

I have been her kind.

I have ridden in your cart, driver,

waved my nude arms at villages going by,

learning the last bright routes, survivor

where your flames still bite my thigh

and my ribs crack where your wheels wind

A woman like that is not ashamed to die.

I have been her kind.

Anne Sexton, "Her Kind" from The Complete Poems of Anne Sexton (Boston: Houghton Mifflin, 1981). @1981 by Linda Gray Sexton and Loring Conant, Jr. Reprinted with the permission of Sterling Lord Literistic, Inc.

Source: The Complete Poems of Anne Sexton (1981).

Anne Sexton (1928-1974) was an American poet of the Confessional school. Throughout her life she had severe depression and was hospitalised on several occasions. She began writing poetry while recovering after a suicide attempt in 1956, as suggested by her therapist, Dr Martin Orne, and almost instantly won great acclaim - her first book, To Bedlam and Part Way Back (1960), was critically praised and nominated for a National Book Award. Sexton's poetry explored childhood guilt, mental illness, motherhood and female sexuality in a candid and unflinching way (she thought that poetry 'should almost hurt'), and is characterised by musical rhythms and striking imagery. She died by asphyxiating herself.

Poem selected by Kasia Krawczyk.

Another of Anne Sexton's poems was published in the November 2008 issue of the Journal. 